\title{
Three-dimensionally Packed Nano-helical Phase in Chiral Block Copolymers
}

\author{
Rong-Ming Ho, Yeo-Wan Chiang, Chi-Chun Tsai, Chu-Chieh Lin, \\ Bao-Tsan Ko, Bor-Han Huang \\ Supporting Information
}

Table S1 Polymerization of PS-PLLA.

Table S2 Characterization of PS-PLLA diblock copolymers.

Figure S1 $\quad{ }^{1} \mathrm{H}$ NMR spectrum of PS280-PLLA127.

Figure S2 (a) TEM micrograph; (b) SAXS profile of PS280-PLLA127 after PLLA crystallization at $110^{\circ} \mathrm{C}$ from melt.

Figure S3 DSC thermograms of (a) isothermal crystallization; (b) melting curves for PS280-PLLA127.

Figure S4 DSC heating thermogram of PS280-PLLA127.

Figure S5 Temperature dependence of real-time SAXS profiles for PS280-PLLA127.

Figure S6 WAXD patterns for PS280-PLLA127 at amorphous and crystalline state.

Figure S7 TEM micrographs of (a) PS198-PLLA28 ( $\left.f_{\text {PLLA }}{ }^{v}=0.14\right)$; (b) PS280-PLLA97 $\left(f_{\mathrm{PLLA}}{ }^{v}=0.29\right)$ and (c) PS125-PLLA167 $\left(f_{\mathrm{PLLA}}{ }^{v}=0.61\right)$.

Figure S8 TEM micrographs of PS280-PLLA127 viewing at different tilting angles. 
A typical free radical polymerization procedure was exemplified by the synthesis of 4-hydroxy-TEMPO-terminated polystyrene. A mixture of styrene (46 mL, $400 \mathrm{mmol}$ ), BPO $(0.39 \mathrm{~g}, 1.6 \mathrm{mmol})$ and 4-OH-TEMPO $(0.33 \mathrm{~g}, 1.92 \mathrm{mmol})$ (molar ratio of 4-OH-TEMPO/BPO $=1.2)$ was preheated in a round-bottom flask $(250 \mathrm{~mL})$ in nitrogen atmosphere at $95{ }^{\circ} \mathrm{C}$ for $3 \mathrm{~h}$ to allow BPO to decompose completely. The system was then heated at $130{ }^{\circ} \mathrm{C}$ for another $4 \mathrm{~h}$ to yield PS-TEMPO-4-OH. The resulting polystyrene was precipitated with methanol $(300 \mathrm{~mL})$ from a $\operatorname{THF}(50 \mathrm{~mL})$ solution. The product was then re-crystallized twice from $\mathrm{CH}_{2} \mathrm{Cl}_{2}(40 \mathrm{~mL}) / \mathrm{MeOH}(200 \mathrm{~mL})$ mixed solution, and collected by vacuum filtration to give white solids. The final solid was washed by $100 \mathrm{~mL} \mathrm{MeOH}$ and dried in vacuum oven overnight to give 4-hydroxy-TEMPO-polystyrene [yield: $32.6 \mathrm{~g}$ (78\%). $\mathrm{Mn}=20900$ and PDI $=1.17 .{ }^{1} \mathrm{H}$ NMR $\left(\mathrm{CDCl}_{3}\right): 6.46-7.09$ (br, 5H, $\left.\mathrm{ArH}\right), 1.84$ (br, $\left.1 \mathrm{H}, \mathrm{CH}), 1.42\left(\mathrm{br}, 2 \mathrm{H}, \mathrm{CH}_{2}\right)\right]$. All manipulations were carried out under a dry nitrogen atmosphere. Solvents, benzoyl peroxide, styrene, L-lactide, and deuterated solvents were purified before uses.

Lithium alkoxide, $\left[\left(\mu_{3}-\mathrm{EDBP}\right) \mathrm{Li}_{2}\right]_{2}\left[\left(\mu_{3}{ }^{\mathrm{n}} \mathrm{Bu}\right) \mathrm{Li}\left(0.5 \mathrm{Et}_{2} \mathrm{O}\right)\right]_{2}$, was prepared according to the method described previously as reported by B.-T. Ko, and C.-C. Lin [ J. Am. Chem. Soc. 2001, 123, 7973].

A typical ring-opening polymerization procedure was exemplified by the synthesis of PS-PLLA. $\left[\left(\mu_{3}-\mathrm{EDBP}\right) \mathrm{Li}_{2}\right]_{2}\left[\left(\mu_{3}-{ }^{\mathrm{n}} \mathrm{Bu}\right) \operatorname{Li}\left(0.5 \mathrm{Et}_{2} \mathrm{O}\right)\right]_{2}(0.11 \mathrm{~g}, 0.1 \mathrm{mmol})$ was added to 4-hydroxy TEMPO-polystyrene $(4.18 \mathrm{~g}, 0.2 \mathrm{mmol})$ in $20 \mathrm{~mL}$ of toluene at $0^{\circ} \mathrm{C}$. The mixture was stirred at room temperature for $2 \mathrm{~h}$, and then dried under vacuum. The resulting product (lithium alkoxide macroinitiator) was dissolved in $\mathrm{CH}_{2} \mathrm{Cl}_{2}(20 \mathrm{~mL})$ and L-lactide 
(2.16 g, $15 \mathrm{mmol})$ in $\mathrm{CH}_{2} \mathrm{Cl}_{2}(10 \mathrm{~mL})$ was added. While the mixture was stirred for $4 \mathrm{~h}$, conversion yield (74\%) of poly(L-lactide) was analyzed by ${ }^{1} \mathrm{H}$ NMR spectroscopic studies. The mixture was then quenched by the addition of an aqueous acetic acid solution $(0.35 \mathrm{~N}$, $20 \mathrm{~mL}$ ) and the polymer was precipitated on pouring into $n$-hexane $(300 \mathrm{~mL})$ to give white solids. The product was purified by precipitation from $\mathrm{CH}_{2} \mathrm{Cl}_{2}(30 \mathrm{~mL}) / \mathrm{Hexane}(150 \mathrm{~mL})$ mixture solution. The final crystalline solid was precipitated from $\mathrm{CH}_{2} \mathrm{Cl}_{2}(30 \mathrm{~mL}) / \mathrm{MeOH}$ $(150 \mathrm{~mL})$ and dried under vacuum at $50-60{ }^{\circ} \mathrm{C}$ overnight to yield $3.02 \mathrm{~g}$ of PS-b-PLA (yield: 48\%). $\mathrm{Mn}=46700$ and $\mathrm{PDI}=1.17 .{ }^{1} \mathrm{H}$ NMR $\left(\mathrm{CDCl}_{3}\right): 6.46-7.09(\mathrm{br}, 5 \mathrm{H}, \mathrm{ArH}), 5.16(\mathrm{q}, 1 \mathrm{H}$, $\left.\mathrm{CH}\left(\mathrm{CH}_{3}\right), \mathrm{J}=7.2 \mathrm{~Hz}\right), 1.84(\mathrm{br}, 1 \mathrm{H}, \mathrm{CH}), 1.58\left(\mathrm{~d}, 3 \mathrm{H}, \mathrm{CH}\left(\mathrm{CH}_{3}\right), \mathrm{J}=7.2 \mathrm{~Hz}\right), 1.42(\mathrm{br}, 2 \mathrm{H}$, $\mathrm{CH}_{2}$ ). ${ }^{1} \mathrm{H}$ and ${ }^{13} \mathrm{C}$ nuclear magnetic resonance (NMR) spectra were recorded on a Varian VXR-300 (300 MHz for ${ }^{1} \mathrm{H}$ and $75 \mathrm{MHz}$ for $\left.{ }^{13} \mathrm{C}\right)$ or a Varian Gemini-200 $\left(200 \mathrm{MHz}\right.$ for ${ }^{1} \mathrm{H}$ and $50 \mathrm{MHz}$ for ${ }^{13} \mathrm{C}$ ) spectrometer with chemical shifts given in ppm from the internal TMS or the central line of $\mathrm{CHCl}_{3}$. The gel permission chromatography (GPC) measurements were performed on a Hitachi L-7100 system equipped with a differential Bischoff 8120 RI detector using THF (HPLC grade) as an eluent. Molecular weight and molecular weight distributions were calculated using polystyrene as standard. The number average molecular weight of 4-hydrolysis-TEMPO terminated PS and polydispersity (PDI) of PS-PLLA block copolymer were obtained by GPC analysis. The molecular weight of PLLA blocks was measured by ${ }^{1} \mathrm{H}$ NMR analysis. Optical rotation data: PS128-PLLA106 $\left(f_{\mathrm{PLLA}}{ }^{v}=0.49\right),[\alpha]^{25}{ }_{254 \mathrm{~nm}}=-78.2^{\circ}\left(\mathrm{CH}_{2} \mathrm{Cl}_{2}, \mathrm{c} 0.05\right) ; \operatorname{PLLA}[\alpha]^{25}{ }_{254 \mathrm{~nm}}=-71.3^{\circ}\left(\mathrm{CH}_{2} \mathrm{Cl}_{2}, \mathrm{c}\right.$ $0.05)$. 
Table S1 Polymerization of L-lactide initiated by lithium alkoxide macroinitiator containing 4-OH-TEMPO-supported polystyrene at $0^{\circ} \mathrm{C}$ for $4 \mathrm{~h}$.

\begin{tabular}{|c|c|c|c|c|c|c|c|}
\hline \multirow{2}{*}{ Entry } & \multicolumn{2}{|c|}{ Prepolymer (GPC) } & \multirow{2}{*}[\mathrm{LA}]{$_{\mathrm{o}} /[\mathrm{PS}-\mathrm{OH}]_{\mathrm{o}}$} & \multirow{2}{*}{$\begin{array}{r}\mathrm{CH}_{2} \mathrm{Cl}_{2} \\
(\mathrm{~mL})\end{array}$} & \multirow{2}{*}{$\begin{array}{l}\text { Conv, } \\
(\%)^{\dagger}\end{array}$} & \multicolumn{2}{|c|}{ Copolymer (GPC) } \\
\hline & $\mathrm{Mn}$ & PDI & & & & $\mathrm{Mn}$ & PDI \\
\hline PS198-PLLA28 & 20900 & 1.17 & 50 & 30 & 69 & 32200 & 1.16 \\
\hline PS280-PLLA67 & 29400 & 1.24 & 75 & 30 & 72 & 57200 & 1.21 \\
\hline PS365-PLLA109 & 38200 & 1.22 & 150 & 50 & 63 & 77400 & 1.20 \\
\hline PS280-PLLA97 & 29400 & 1.24 & 125 & 40 & 65 & 64400 & 1.25 \\
\hline PS197-PLLA72 & 20700 & 1.17 & 75 & 30 & 81 & 40400 & 1.24 \\
\hline PS280-PLLA127 & 29400 & 1.24 & 125 & 30 & 76 & 73600 & 1.22 \\
\hline PS122-PLLA118 & 12900 & 1.16 & 100 & 20 & 88 & 40400 & 1.28 \\
\hline PS125-PLLA151 & 13300 & 1.08 & 80 & 30 & 78 & 50300 & 1.11 \\
\hline PS125-PLLA167 & 13300 & 1.08 & 94 & 30 & 79 & 52200 & 1.16 \\
\hline
\end{tabular}

$\dagger$ As determined via integration. 


\section{S4}

Table S2 Characterization of PS-PLLA block copolymers

\begin{tabular}{lcccccc}
\hline \multicolumn{1}{c}{ Code } & $\begin{array}{c}\text { Mn,PS } \\
(\mathrm{g} / \mathrm{mol})^{\dagger}\end{array}$ & $\begin{array}{c}\text { Mn,PLLA } \\
(\mathrm{g} / \mathrm{mol})^{\ddagger}\end{array}$ & $f_{\mathrm{PS}}{ }^{\nu}$ & $f_{\mathrm{PLLA}}{ }^{v}$ & $\begin{array}{c}\text { Total Mn } \\
(\mathrm{g} / \mathrm{mol})^{\S}\end{array}$ & Nanostruture \\
\hline PS198-PLLA28 & 20900 & 3960 & 0.86 & 0.14 & 24860 & BCC \\
PS280-PLLA67 & 29400 & 9650 & 0.78 & 0.22 & 39050 & HC \\
PS365-PLLA109 & 38200 & 15700 & 0.74 & 0.26 & 77400 & HC \\
P280-PLLA97 & 29400 & 14000 & 0.71 & 0.29 & 43400 & HC \\
PS197-PLLA72 & 20700 & 10300 & 0.70 & 0.30 & 31000 & HC \\
PS280-PLLA127 & 29400 & 18300 & 0.65 & 0.35 & 47700 & Helices \\
PS128-PLLA106 & 13600 & 15300 & 0.51 & 0.49 & 28900 & L \\
PS122-PLLA118 & 12900 & 17000 & 0.47 & 0.53 & 29900 & L \\
PS125-PLLA167 & 13300 & 24100 & 0.39 & 0.61 & 37400 & L \\
\hline
\end{tabular}

$\dagger$ Obtained from GPC analysis. $†$ Obtained from ${ }^{1} \mathrm{H}$ NMR measurement. §Obtained from $\dagger$ plus $\$$. 

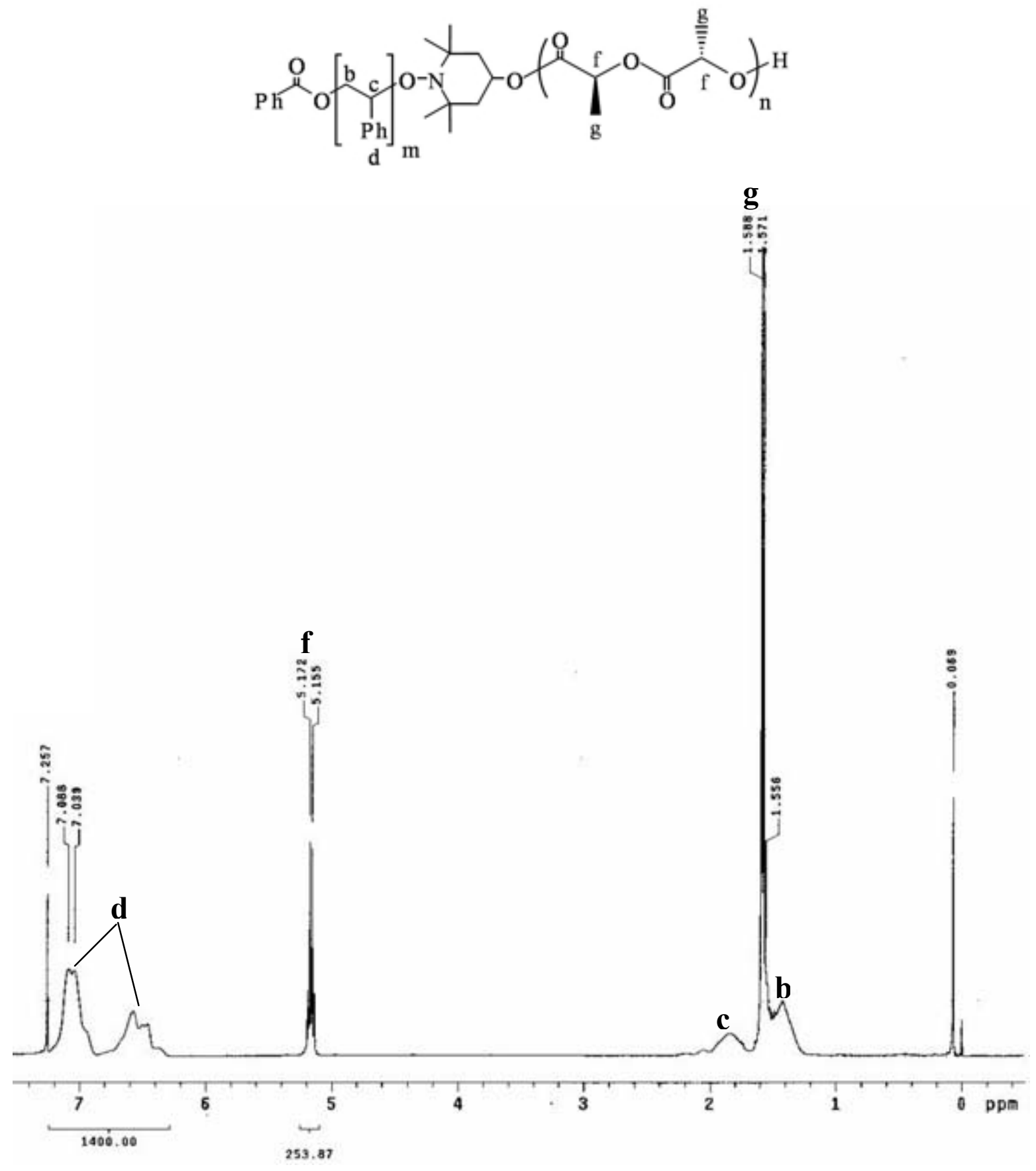

Figure. S1. ${ }^{1}$ H NMR spectrum of PS280-PLLA127. 
Crystallization of PLLA in PS-PLLA gave rise to significant change for microphase-separated morphology of PS-PLLA as observed in our laboratory. To eliminate the disturbance of PLLA crystallization on formed morphology, cast samples were annealed at temperature above PLLA melting $\left(165^{\circ} \mathrm{C}\right.$ for three minutes) but below order-disorder transition temperature, and then rapidly cooled at a rate of $150^{\circ} \mathrm{C} / \mathrm{min}$ to room temperature. No significant degradation was found as evidenced by GPC analysis. The order-disorder transition temperature of PS-PLLA was above degradation temperature $\left(\sim 170{ }^{\circ} \mathrm{C}\right)$ as identified by SAXS. SAXS experiments were conducted at the synchrotron X-ray beam-line X27C at the National Synchrotron Light Source in Brookhaven National Laboratory. Time-resolved SAXS experiments were carried out in a heating chamber with step temperature increasing. Degradation temperature was identified by the disappearance of scattering peaks.

The orientation of single-domain-like block copolymer nanostructures was achieved by specific solution-cast method where the evaporation rate of solvent was well controlled to form oriented microdomains upon microphase separation. Similar results have been reported [Libera, M. et al. Macromolecules 1998, 31, 2569.]. Bulk samples of block copolymers were prepared by solution casting from dichloromethane $\left(\mathrm{CH}_{2} \mathrm{Cl}_{2}\right)$ solution (10 wt $\%$ of PS-PLLA) at room temperature in a beaker well sealed by aluminum foil having punch holes for vapor releasing. Samples with oriented nanostructures were obtained from the wall of the beaker.

Transmission electron microscopy in bright field was performed with JEOL TEM-1200x transmission electron microscopy. Staining was accomplished by exposing the samples to the vapor of a $4 \%$ aqueous $\mathrm{RuO}_{4}$ solution for 3 hours. No significant exothermic response was observed by differential scanning calorimetry (DSC) under fast cooling for the quenched samples. WAXD diffraction exhibited amorphous-like diffraction profile. 

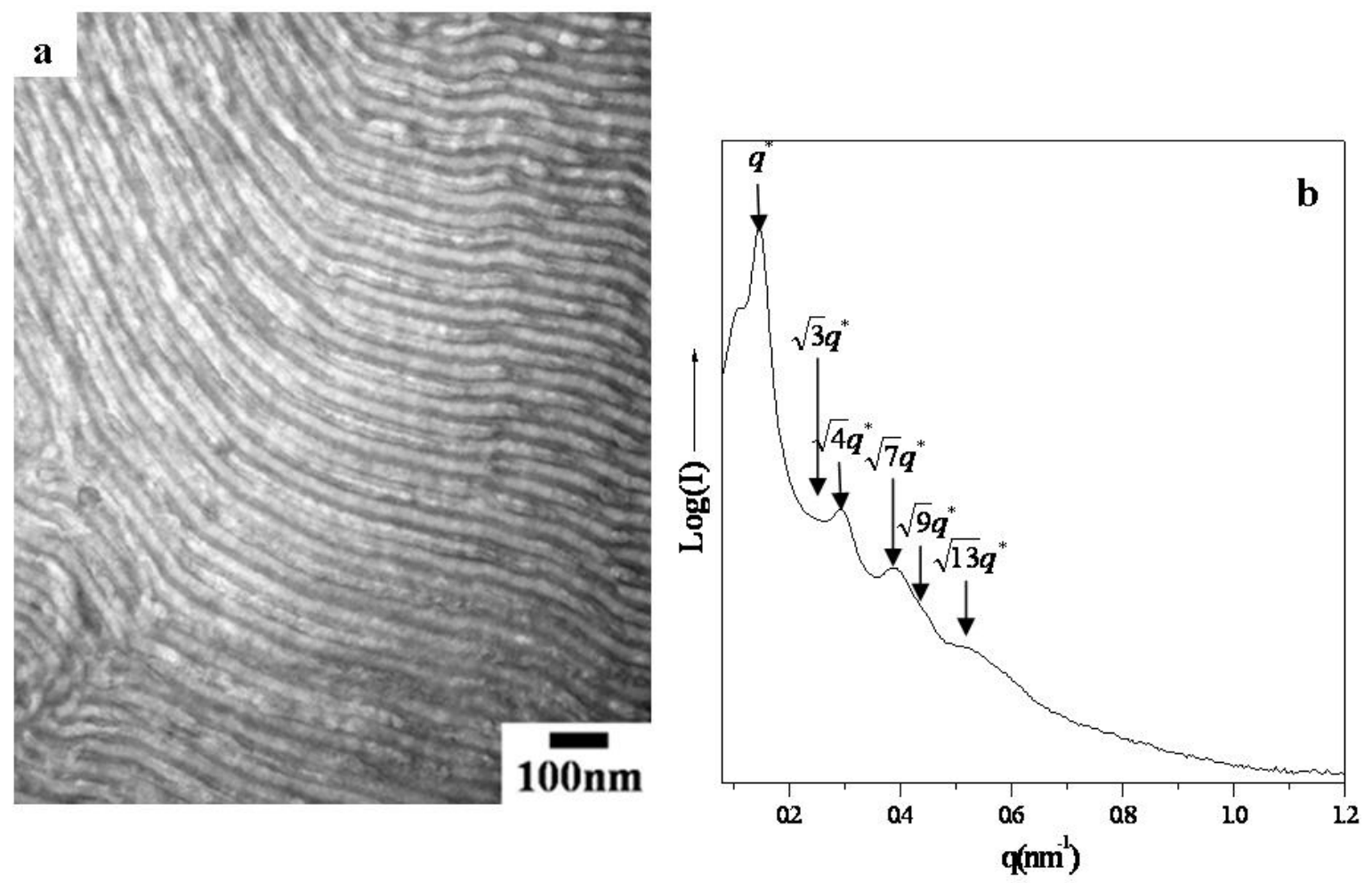

Figure. S2 . (a) TEM micrograph; (b) SAXS profile of PS280-PLLA127 $\left(f_{\mathrm{PLLA}}{ }^{v}=0.35\right)$ after PLLA crystallization at $110^{\circ} \mathrm{C}$ from melt. As shown, the helical nanostructures were transformed to cylindrical-like morphology after PLLA crystallization. 

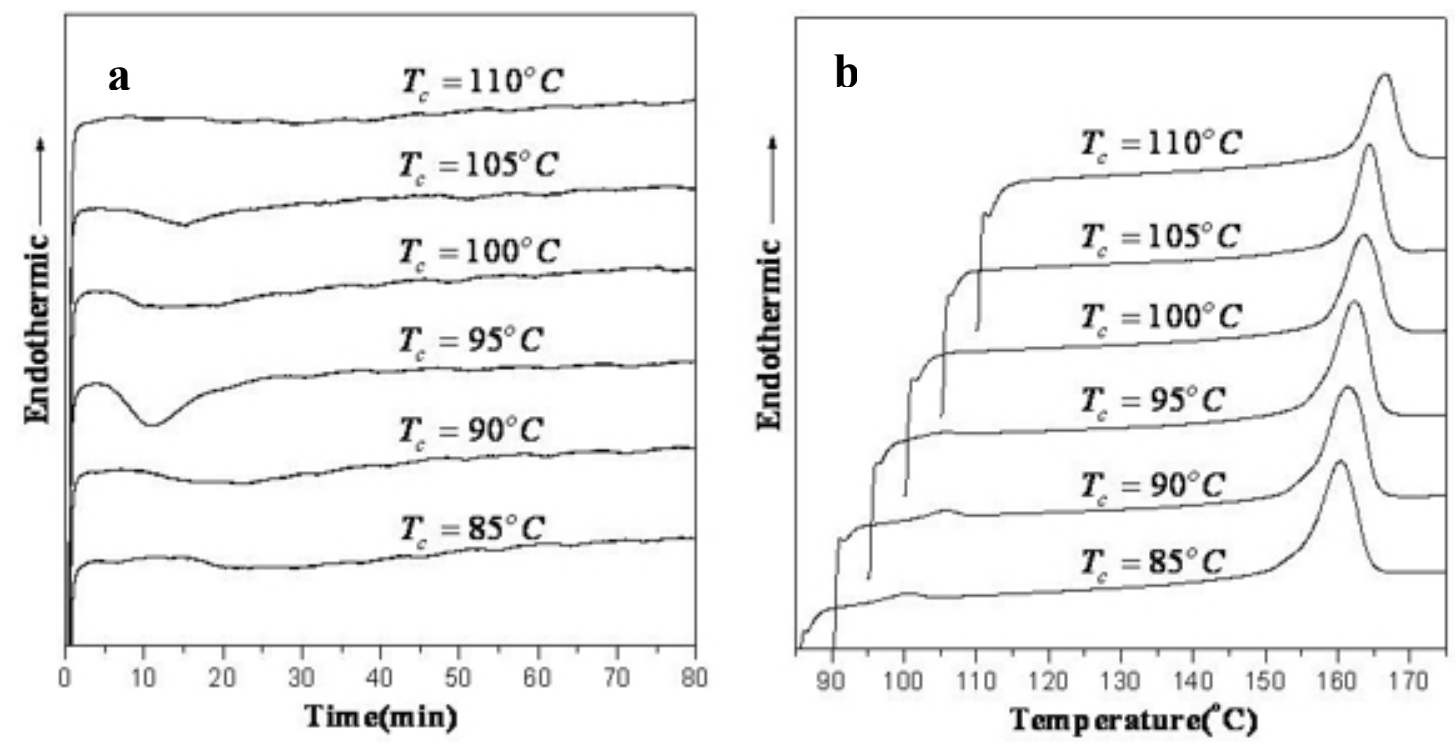

Figure. S3. DSC thermograms of (a) isothermal crystallization; (b) melting curves for PS280-PLLA127 $\left(f_{\text {PLLA }}{ }^{v}=0.35\right)$ at different crystallization temperatures. On the basis of the reciprocal time of exothermic peak, the maximum crystallization rate is estimated at ca. $95^{\circ} \mathrm{C}$. The melting point increases with increasing crystallization temperature. 


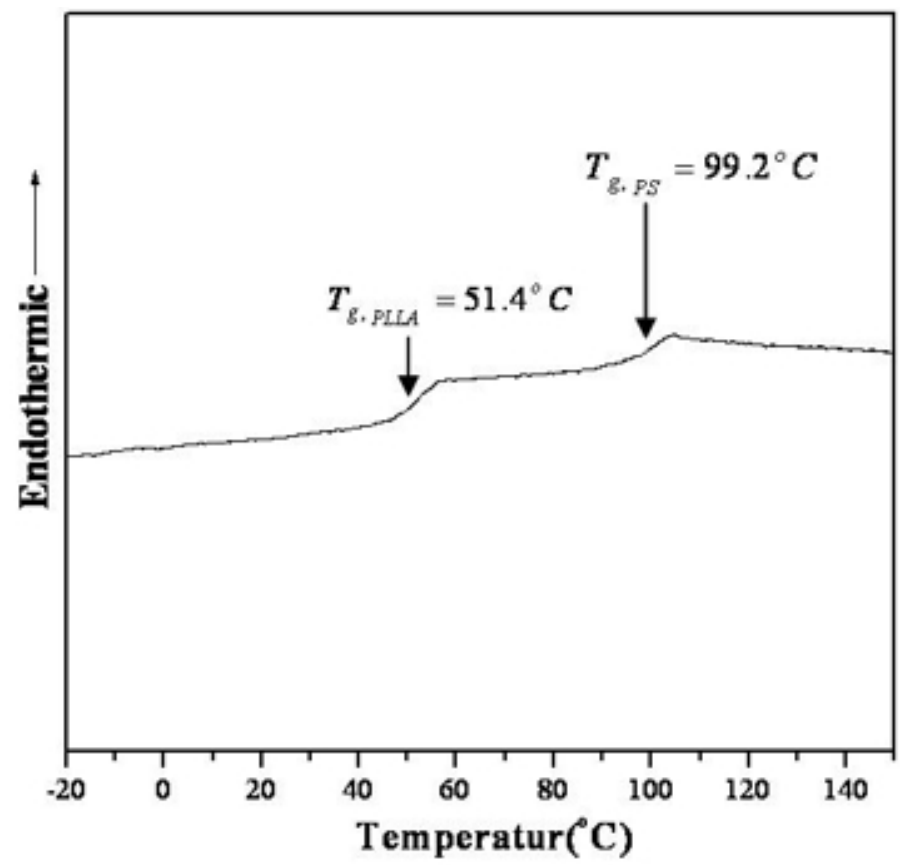

Figure. S4. DSC heating thermogram of PS280-PLLA127 $\left(f_{\mathrm{PLLA}}{ }^{\nu}=0.35\right)$. The sample was first heating to $165^{\circ} \mathrm{C}$ and then quenched by a rate of $150^{\circ} \mathrm{C} / \mathrm{min}$ to $-50^{\circ} \mathrm{C}$. Glass transition temperatures of PLLA and PS blocks were clearly identified. The heating rate is $10^{\circ} \mathrm{C} / \mathrm{min}$. 


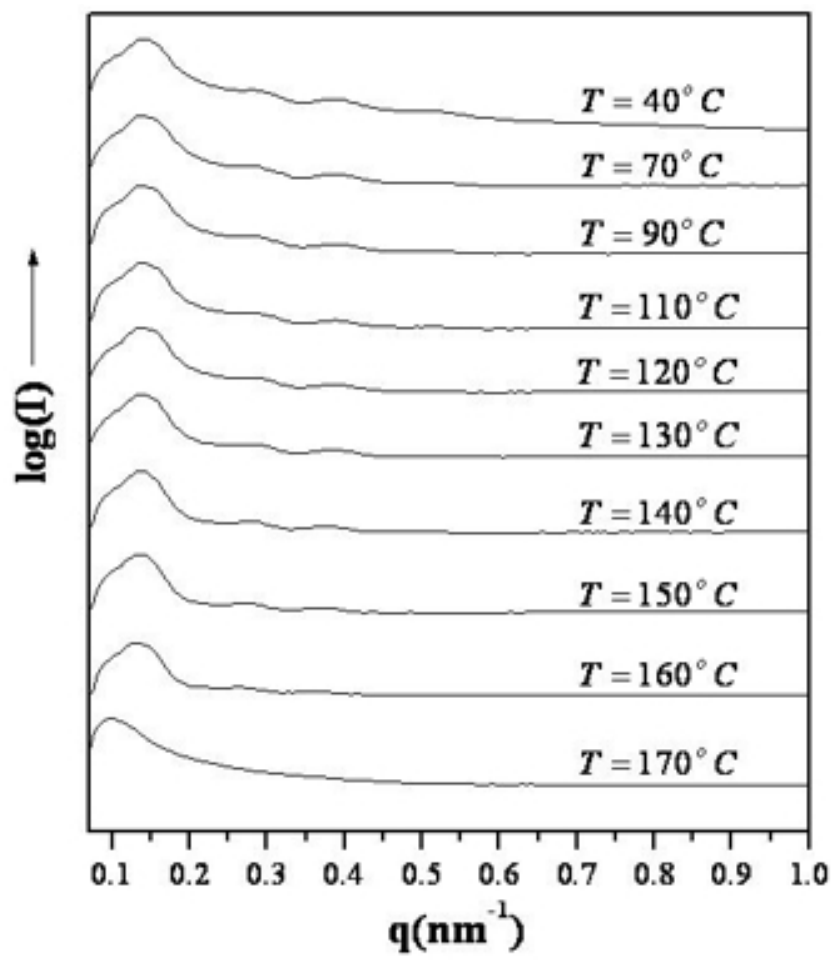

Figure. S5. Temperature dependence of real-time SAXS profiles for PS280-PLLA127 $\left(f_{\text {PLLA }}{ }^{v}=0.35\right)$. As shown, the diffraction results of phase-separated nanostructures sustain up to $160^{\circ} \mathrm{C}$. Degradation temperature was identified by the shift of diffraction peak that is around $170^{\circ} \mathrm{C}$. The heating rate is $30^{\circ} \mathrm{C} / \mathrm{min}$. 


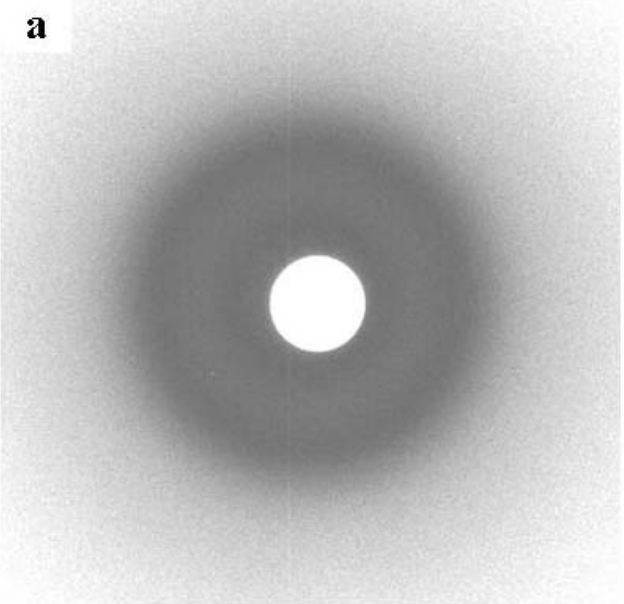

b

Figure. S6. Two-dimensional WAXD patterns of PS280-PLLA127 $\left(f_{\mathrm{PLLA}}{ }^{v}=0.35\right)$ at (a) amorphous state; (b) crystalline state. 

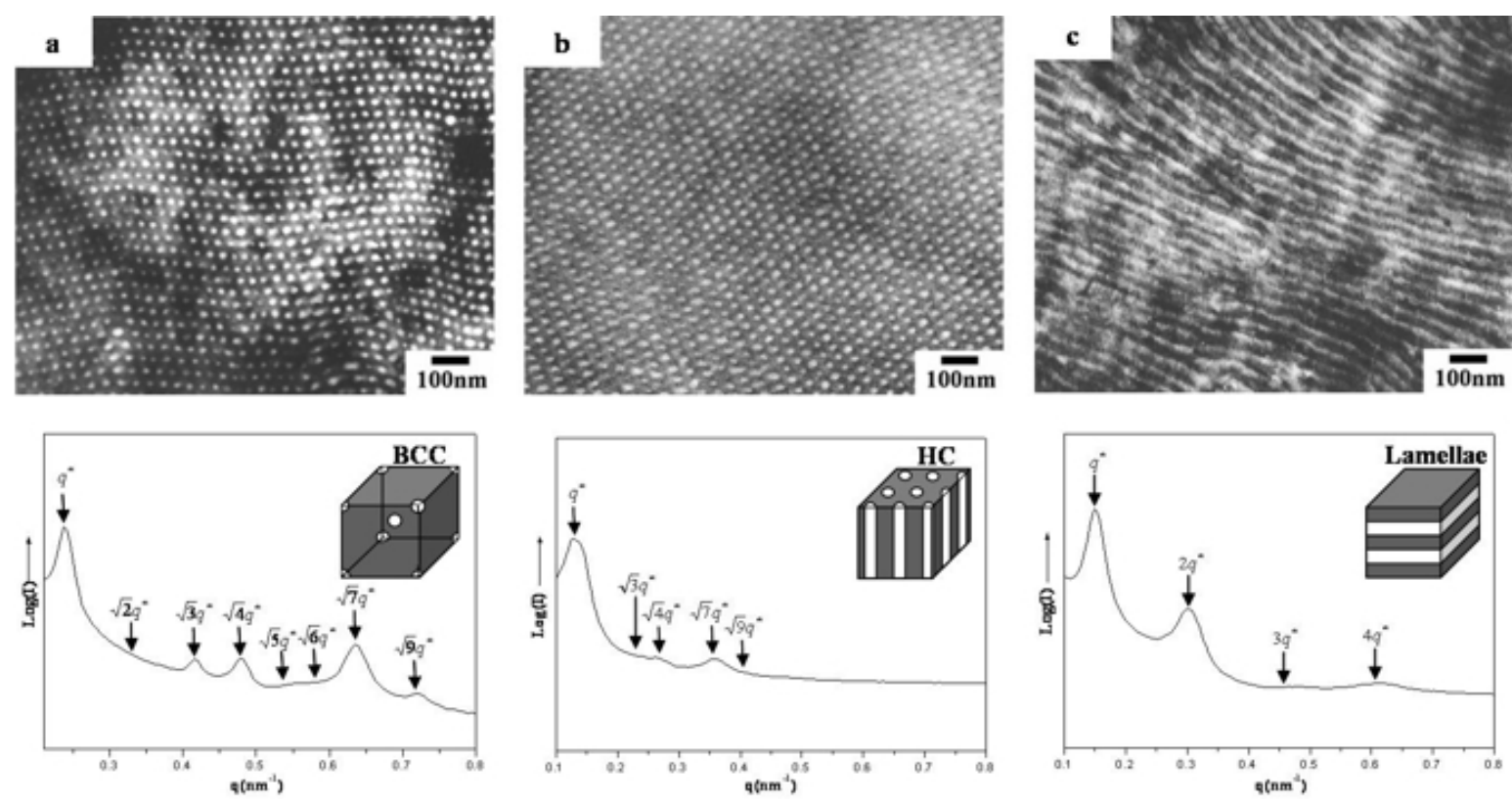

Figure S7. TEM micrographs of (a) PS198-PLLA28 ( $\left.f_{\text {PLLA }}{ }^{v}=0.14\right)$; (b) PS280-PLLA97 $\left(f_{\text {PLLA }}{ }^{v}=0.29\right)$ and (c) PS125-PLLA167 $\left(f_{\text {PLLA }}{ }^{v}=0.61\right)$. The microdomains of PS component appear relatively dark after staining by $\mathrm{RuO}_{4}$, while the microdomains of PLLA component appear light. The corresponding azimuthal integrated one-dimensional SAXS profiles are also obtained as shown. The diffraction results further confirm the observed nanostructures where the scattering peaks of body-centered cubic sphere, hexagonal cylinder and lamellae occur at $q^{*}$ ratio of $1: \sqrt{2}: \sqrt{3}: \sqrt{4}$, at $q^{*}$ ratio of $1: \sqrt{3}: \sqrt{4}: \sqrt{7}: \sqrt{9}$ and at $q^{*}$ ratio of $1: 2$ : 3: 4 , respectively. 
Thin-film samples with cross section cutting at specific angle to the helical axes of hexagonally packed texture were observed under TEM at different tilting angles. After tilting from the arrays of helical axes, the projected images of helical morphology can be identified under appropriate tilting stages.
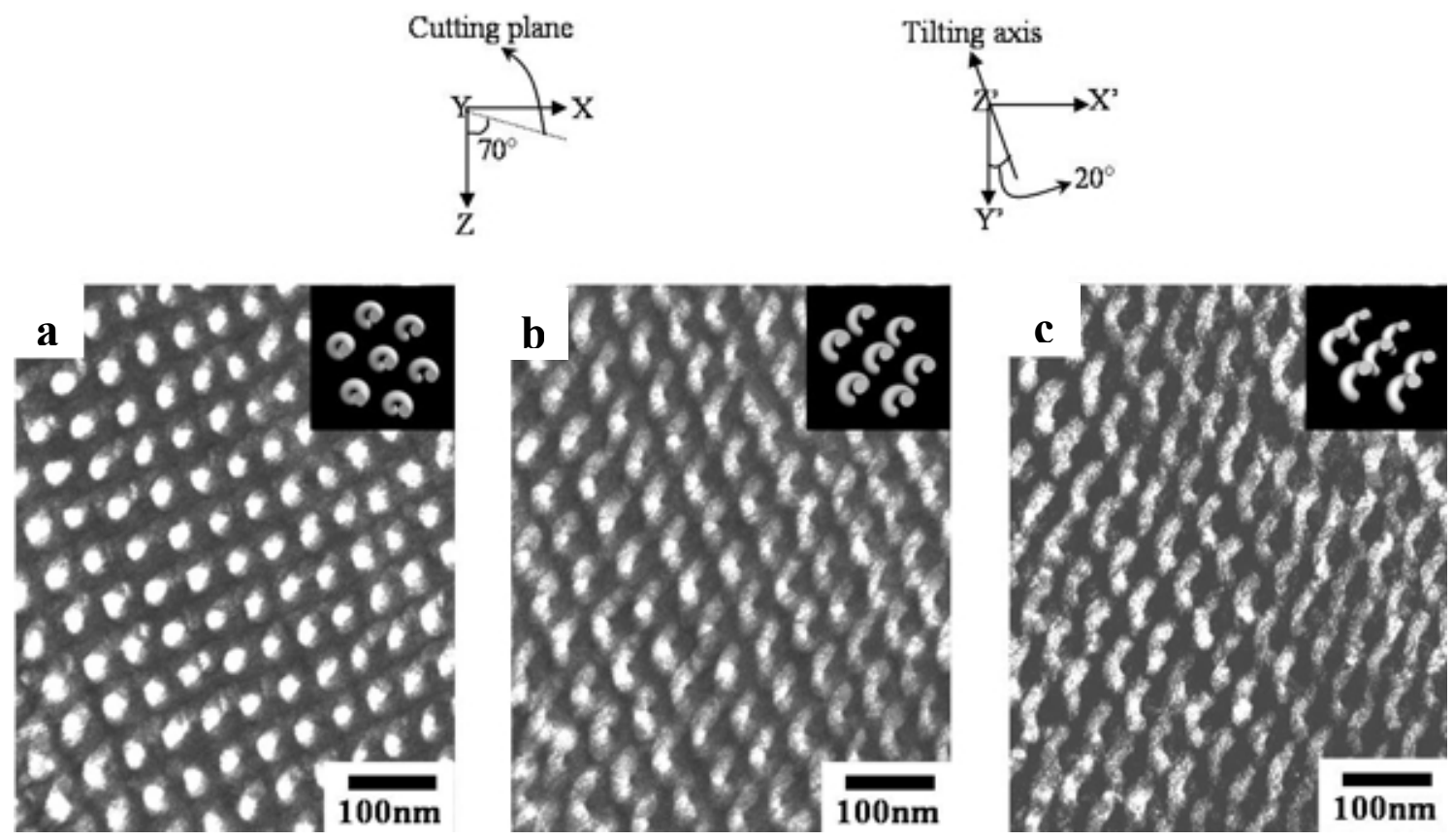

Figure. S8. TEM micrographs of PS280-PLLA127 $\left(f_{\mathrm{PLLA}}{ }^{\nu}=0.35\right)$ viewing at tilting angles of (a) $0^{\circ}$; (b) $20^{\circ}$; (c) $40^{\circ}$. The initial thin-film section was cut along the plane ca. 70 degree off the (100) plane of helical phase as shown. The Z-axis is the helical axis. The inset figures show the schematic illustration of projected images for thin-film sections of helical phase at indicated viewing angle off the tilting axis as shown. The $Z$ '-axis is normal direction to thin-film sample surface. 